\title{
PEMETAAN SUBSTRAT DASAR PERAIRAN DANGKAL DI KECAMATAN TAYANDO KOTA TUAL MENGGUNAKAN CITRA LANDSAT 8
}

(The Bottom Substrate Shallow Water Mapping Using Landsat 8 Imagery)

\author{
Marvin Mario Makailipessy dan Fabian Souisa \\ Program Studi Teknologi Penangkapan Ikan \\ Politeknik Perikanan Negeri Tual \\ e-mail: mariomarvin.mm@gmail.com
}

\begin{abstract}
This study aimed to determine mapped of the substrate (habitat) of the bottom shallow waters at Tayando District, Tual City with Landsat 8 imagery satellite. We used transformation blue and green bands with depth invariant index algorithm $\mathrm{Y}=\ln$ Band $1+$ $(\mathrm{ki} / \mathrm{kj})$ In Band 2 on mapped the basic characteristics of the bottom shallow water. The classification of the imagery transformation by using shallow marine water habitat classification scheme based on color pallet and the result showed there were five classes on bottom substrate at Tayando District, those were sand, sand mixed coral, dead coral, coral reefs and seagrass.
\end{abstract}

Keywords: Bottom Shallow Water, Landsat 8 Imagery

\section{PENDAHULUAN}

Penginderaan jauh (remote sensing) adalah teknik yang dikembangkan untuk memperoleh dan menganalisis informasi tentang bumi dimana informasi tersebut khusus berbentuk radiasi gelombang elektromagnetik yang dipancarkan atau dipantulkan dari permukaan bumi (Sutanto, 1992 dalam Suhana, 2015). Menurut Lillesand dan Kiefer (1990) penginderaan jauh adalah ilmu dan seni untuk memperoleh informasi tentang obyek, daerah atau fenomena melalui analisis data yang diperoleh dengan alat tanpa adanya kontak langsung dengan obyek, daerah atau fenomena yang dikaji. Perkembangan ilmu penginderaan jarak jauh dari tahun ke tahun mengalami perkembangan yang cukup pesat, sehingga manusia akan selalu mengembangkan kemampuannya dalam mengembangkan citra satelit agar dapat dipergunakan untuk kepentingan-kepentingan lainnya yang erat kaitannya dengan perolehan informasi suatu objek, daerah ataupun fenomena geografisnya (Bhian, 2010 dalam Suhana, 2015).
Beberapa penelitian terdahulu seperti Pasaribu (2008) perubahan luasan terumbu karang, Siregar (2010) pemetaan substrat dasar perairan dangkal, Damayanti (2012) pemetaan terumbu karang, Marendy (2013) studi distribusi terumbu karang, Suhana (2015) pemetaan sebaran dan kondisi terumbu karang, merupakan beberapa penelitian yang mengunakan aplikasi pengindraan jauh berbasis citra satelit untuk mendeteksi berbagai fitur-fitur di ekosistem perairan dangkal seperti lamun, algae, substrat dasar perairan dan terumbu karang.

Citra merupakan masukan data atau hasil observasi dalam proses penginderaan jauh. Citra dapat diartikan sebagai gambaran yang tampak dari suatu objek yang diamati, sebagai hasil liputan atau rekaman suatu alat pemantau/sensor, baik optik, elektrooptik, optik mekanik maupun elektro magnetik. Citra memerlukan proses interpretasi atau penafsiran terlebih dahulu dalam pemanfaatannya (Helmi et al, 2011). Citra satelit merupakan hasil dari pemotretan/perekaman alat sensor yang dipasang pada wahana satelit ruang angkasa 
dengan ketinggian lebih dari $400 \mathrm{~km}$ dari permukaan bumi (Helmi et al, 2011).

Oleh karena itu, pemanfaatan citra satelit dalam mendeteksi substrat dasar perairan khususnya di perairan Kecamatan Tayando Kota Tual terasa perlu dilakukan karena berbagai penelitian yang telah dijabarkan sebelumnya dilakukan di sebagian besar wilayah barat dan tengah indonesia, dan untuk penelitian pengindraan jauh menggunakan citra satelit landsat 8 belum banyak dilakukan.

Tujuan penelitian ini adalah untuk mengelola/menganalisis citra satelit landsat 8 dalam menentukan dan memetakan substrat dasar perairan dangkal di Kecamatan Tayando Kota Tual.

\section{METODE PENELITIAN}

\section{Lokasi dan Metode Penelitian}

Lokasi penelitian yang digunakan dalam pemetaan substrat dasar perairan dangkal yaitu pada Kecamatan Tayando yang terdiri dari tujuh pulau kecil (P. Walir, P. Heniar, P. Ree, P. Nya, P. Nusreen, P. Taam, dan P. Tayando). Penelitian ini dilakukan pada Bulan Maret 2015. Citra satelit yang digunakan adalah citra Landsat
8 dengan tanggal akusisi 27 Juli 2014. Kanal yang dipakai adalah kanal 1, kanal 2, kanal 3 dan kanal 4 (pemisahan laut dan darat), alogaritma yang digunakan adalah alogaritma lygenza dalam Guntur et.al (2012). Alat dan bahan yang digunakan adalah satu buah laptop acer, koneksi internet (modem), perangkat lunak pemrosesan data citra, perangkat lunak sistem informasi geografis (SIG), perangkat lunak office dan printer.

\section{Pengambilan Data}

Pengambilan data citra landsat 8 dilakukan melalui salah satu situs milik USGS yang menyediakan layanan citra open access dan gratis. Path 106 dan row 64 dengan tanggal akusisi 27 Juli 2014 merupakan path row citra untul wilayah sekitar lokasi penelitian. Data citra landsat 8 berukuran hampir 1GB dimana membutuhkan kecepatan internet yang sangat baik dalam proses pengunduhan dan komputer diinstal program java. Data citra landsat 8 terdiri dari 11 band dimana masing masing band memiliki spefikasi tersendiri (gambar 1).

\begin{tabular}{|c|c|c|}
\hline \multicolumn{2}{|l|}{ LDCM OLI/TIRS Band Requirements } & \multirow{2}{*}{ +Explanation of Differences } \\
\hline $30 \mathrm{~m}$, Coestal/Aerosol, $0.433-0.453 \mu \mathrm{m}\left({ }^{\circ} \mathrm{A}\right)$ & Band 1 & \\
\hline $30 \mathrm{~m}$, Blue, $0.450-0.515 \mu \mathrm{m}$ & Band 2 & \multirow{2}{*}{$\begin{array}{l}\text { Coastal Band added at request of ocean color } \\
\text { investigators requiring higher resolution of coastal } \\
\text { waters relative to MODIS and SeaWiFS. }\end{array}$} \\
\hline $30 \mathrm{~m}$, Green, $0.525-0.600 \mu \mathrm{m}$ & Band 3 & \\
\hline $30 \mathrm{~m}$, Red, $0.630-0.680 \mu \mathrm{m}\left({ }^{\circ} \mathrm{B}\right)$ & Band 4 & \multirow{3}{*}{$\begin{array}{l}\text { Bandwidth refinements made to avoid atmospheric } \\
\text { absorption features (enabled by the higher signal-to- } \\
\text { noise ratio inherent in push-broom architecture). }\end{array}$} \\
\hline $30 \mathrm{~m}$, Near-1R, $0.845-0.885 \mu \mathrm{m}$ ("B) & Band 5 & \\
\hline $30 \mathrm{~m}, \mathrm{SWIR}-1,1.560-1.680 \mu \mathrm{m}$ ('B) & Band 6 & \\
\hline $30 \mathrm{~m}, \mathrm{SW} / \mathrm{R}-2,2.100-2.300 \mu \mathrm{m}$ ("'B) & Band 7 & \multirow{2}{*}{$\begin{array}{l}\text { Cirrus Band added to detect cirrus contamination in } \\
\text { other channels. }\end{array}$} \\
\hline $15 \mathrm{~m}, \operatorname{Pan} 0.500-0.680 \mu \mathrm{m}\left({ }^{\circ} \mathrm{B}\right)$ & Band 8 & \\
\hline $30 \mathrm{~m}$, Cirus, $1.360-1.390 \mu \mathrm{m}\left({ }^{\circ} \mathrm{C}\right)$ & Band 9 & \multirow{3}{*}{$\begin{array}{l}\text { TIRS wil acquire the data for these two thermal } \\
\text { bands. }\end{array}$} \\
\hline $100 \mathrm{~m}, \mathrm{LW} / \mathrm{R}-1,10.30-11.30 \mu \mathrm{m}$ ('D) & Band 10 & \\
\hline $100 \mathrm{~m}, \mathrm{LW} \mid \mathrm{R}-2,11.50-12.50 \mu \mathrm{m}\left({ }^{\circ} \mathrm{D}\right)$ & Band 11 & \\
\hline
\end{tabular}

Gambar 1. Spefikasi band-band pada citra landsat 8 (sumber : USGS.gov)

Menurut Guntur et.al (2012) proses pengolahan data citra terdiri dari :

a. Pemilihan wilayah yang akan dipetakan (crooping),

b. Memasukkan alogaritma dari statistik citra yang berfungsi untuk proses masking, c. Masking untuk memisahkan lautan dari daratan,

d. Proses perhitungan alogaritma lygenza di perangkat lunak office untuk mempertajam citra agar hasilnya lebih baik, 
e. Pemasukan alogaritma yang telah diolah untuk perhitungan alogaritma lygenza selanjutnya,

f. Klasifikasi palet warna untuk mengumpulkan objek homogen

g. Digitasi untuk memotong citra yang terklasifikasi agar mudah diolah pada perangkat lunak SIG.

h. Pengolahan di perangkat lunak SIG untuk mengolah, menganalisis, menampilkan data serta membuat peta serta laporan yang berkaitan dengan data spasial yang bereferensi geografis.

\section{Analisis Data}

Proses analisa data meliputi analisa data citra landsat 8, informasi tentang distribusi spasial karakteristik dasar perairan dangkal diekstrak dari citra satelit menggunakan Algoritma "depth-invariant bottom index" yang mengeliminir faktor kedalaman (koreksi kolom air). Indeks ini dapat digunakan sebagai indeks karakteristik dasar perairan. Analisa citra menggunakan alogaritma lygenza, dimana koefisien antenuasinya harus dicari terlebih dahulu. Menurut Guntur et al (2012) alogaritma lygenza berfungsi untuk mempertajam citra agar peta yang dihasilkan lebih baik yang didasarkan pada varian (ragam) dan kovarian (peragam) yaitu:

$\frac{K i}{K j}=a+\sqrt{a^{2}}+1$

$a=\frac{(\text { Varian Band } 1-\text { Varian Band } 2)}{(2 \times \text { Covarian Band } 1 \text { Band } 2}$

Rumus transformasi lygenza :

$\mathrm{Y}=\ln$ Band $1+(\mathrm{ki} / \mathrm{kj})^{*} \ln$ band 2

Dimana $\mathrm{Y}=$ indeks dasar perairan, $\mathrm{ki} / \mathrm{kj}=$ koefisien antenuasi. Langkah selanjutnya dilakukan interpretasi bentuk lahan secara visual melalui laptop dengan menggunakan unsur-unsur interpretasi dan fasilitas memperbesar dan memperkecil liputan citra yang ada pada laptop agar lebih detail dan dapat diamati. Fungsi multispektral dilakukan dengan memilih 3 band, yaitu untuk membuat citra warna komposit dengan memasukkan setiap band kedalam filter merah, hijau dan biru (RGB), dan dari kombinasi tersebut diharapkan dapat menyajikan keragaman warna paling banyak agar diperoleh informasi yang optimal.

\section{HASIL DAN PEMBAHASAN}

Berdasarkan hasil perhitungan maka nilai perhitungan koefisien antenuasi perairan diperoleh nilai $(\mathrm{ki} / \mathrm{kj})$ yaitu sebesar 0,757. Dengan demikian persamaan alogaritma yang digunakan untuk mengekstrak substrat dasar perairan menjadi $\mathrm{Y}=\ln$ Band $1+0.757 * \ln$ Band 2. Dari citra hasil transformasi alogaritma kemudian menggunakan palet warna rainbow maka secara visual dapat dibedakan dengan jelas objek pasir (merah), lamun (seagrass) dicirikan dengan warna oranye, karang hidup berwarna biru muda, karang mati berwarna hijau dan pasir campur patahan karang mati dengan gradasi warna kuning kehijau-hijauan (mengacu pada Sulma dan Winarso, 2003).

Tabel 1. Luasan substrat dasar perairan berdasarkan citra satelit Landsat 8

\begin{tabular}{|l|r|r|}
\hline Habitat Dasar & $\begin{array}{c}\text { Jumlah } \\
\text { Pixel }\end{array}$ & Luasan $\left(\mathrm{m}^{2}\right)$ \\
\hline Lamun & 9.312 & 8.380 .800 \\
\hline $\begin{array}{l}\text { Terumbu } \\
\text { Karang }\end{array}$ & 23.090 & 20.781 .000 \\
\hline Karang mati & 6.878 & 6.190 .200 \\
\hline $\begin{array}{l}\text { Pasir campur } \\
\text { patahan karang } \\
\text { mati }\end{array}$ & 54.466 & 49.019 .400 \\
\hline Pasir halus & 20.978 & 18.880 .200 \\
\hline
\end{tabular}

Berdasarkan data pada tabel 1 terlihat bahwa substrat perairan dasar kecamatan Pulau Tayando dimonasi oleh substrat pasir campur patahan karang mati dengan jumlah pixel 54.466 pixel dengan 
luasan 49.019.400 $\mathrm{m}^{2}$, sedangkan terkecil didominasi oleh lamun dengan jumlah pixel sebesar 9.312 pixel dengan luasan
$8.380 .800 \mathrm{~m}^{2}$. Persentase masing-masing kelas substrat dasar perairan (gambar 2).

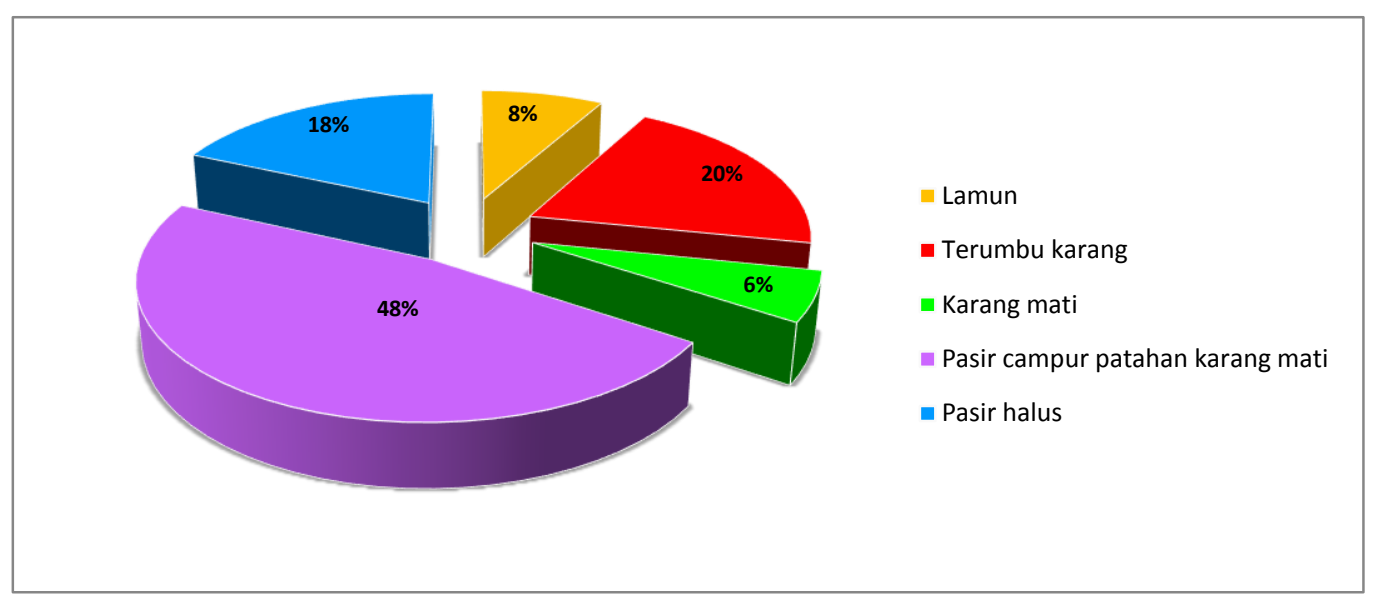

Gambar 2. Persentase kelas substrat dasar perairan Kecamatan Tayando

Berdasarkan gambar 1 maka terlihat dengan jelas bahwa kelas substrat dasar perairan kecamatan Tayando didominasi oleh pasir campur patahan karang mati dimana hampir 50\% substrat dasar perairan dangkal didominasi oleh substrat ini atau seluas 4.901,94 $\mathrm{Ha}$, diikuti dengan terumbu karang dengan persentase $20 \%$ atau seluas 2.078,10 $\mathrm{Ha}$, pasir halus 18\% atau seluas 1.888,02 $\mathrm{Ha}$, lamun sebesar $8 \%$ atau seluas $838,02 \mathrm{Ha}$ dan terkecil ditempati oleh substrat dasar karang mati sebesar 6\% atau seluas 619,02 Ha. Secara spasial kondisi penyebaran substrat dasar perairan dangkal Kecamatan Tayando (gambar 3).

Berdasarkan gambar 3 maka secara visual luasan substrat dasar pasir halus terluas pada Pulau Nusreen dan terkecil luasannya pada Pulau Taam. Untuk substrat dasar pasir campur patahan karang mati terluas pada Pulau Tayando dan luasan terkecil pada Pulau Taam. Luasan karang mati untuk keseluruhan pulau tidak berbeda jauh untuk masingmasing pulau. Wilayah Pulau Nya dan Nusreen secara visual memiliki luasan terumbu karang yang luas dibandingkan dengan pulau lainnya. Substrat atau habitat lamun terluas dimiliki oleh Pulau Nya sedangkan terkecil luasnya pada Pulau Taam. Keadaan substrat atau habitat di suatu perairan dangkal sangat dipengaruhi oleh faktor-faktor oseanografi suatu perairan, kedalaman dan musim dimana pada musim-musim tertentu pada pulaupulau tertentu mengalami hantaman gelombang.

Penggunaan citra satelit landsat 5 dan 7 untuk penelitian pengindraan jauh khususnya di bidang kelautan sudah banyak dilakukan seperti Sirajuddin et al tentang perubahan morfologi laut, Joyce et al (2004) kombinasi landsat ETM+ berhubungan dengan klasifikasi terumbu karang, Budiman dan Hasyim (2005) tentang pemetaan sebaran ekosistem pesisir dan masih banyak yang lainnya, namun untuk landsat 8 masih kurang dilakukan karena satelit landsat ini sendiri baru diluncurkan pada tahun 2013. Dibandingkan versi-versi sebelumnya, landsat 8 memiliki beberapa keunggulan khususnya terkait spesifikasi band-band yang dimiliki maupun panjang rentang spektrum gelombang elektromagnetik yang ditangkap sehingga sensitif terhadap perbedaan reflektan air laut atau aerosol. Band ini unggul dalam membedakan konsentrasi aerosol di atmosfer dan mengidentifikasi karakteristik tampilan air laut pada kedalaman berbeda (Sugiarto, 2013). 
Sebelumnya kita mengenal tingkat keabuan (Digital Number-DN) pada citra landsat berkisar antara 0-256. Dengan hadirnya landsat 8 , nilai DN memiliki interval yang lebih panjang, yaitu 0-4096. Kelebihan ini merupakan akibat dari peningkatan sensitifitas landsat dari yang semula tiap piksel memiliki kuantifikasi 8 bit, sekarang telah ditingkatkan menjadi 12 bit. Tentu saja peningkatan ini akan lebih membedakan tampilan obyek-obyek di permukaan bumi sehingga mengurangi terjadinya kesalahan interpretasi. Tampilan citra pun menjadi lebih halus, baik pada band multispektral maupun pankromatik (Sugiarto, 2013).

Terkait resolusi spasial, landsat 8 memiliki kanal-kanal dengan resolusi tingkat menengah, setara dengan kanalkanal pada landsat 5 dan 7. Umumnya kanal pada OLI memiliki resolusi $30 \mathrm{~m}$, kecuali untuk pankromatik $15 \mathrm{~m}$. Dengan demikian produk-produk citra yang dihasilkan oleh landsat 5 dan 7 pada beberapa dekade masih relevan bagi studi data time series terhadap landsat 8 (Sugiarto, 2013).

Mumby et al (1997) menjelaskan tingkat akurasi landsat TM dimana untuk terumbu karang akurasinya sebesar $86 \%$, alga 47\%, pasir 83\%, dan lamun sebesar 59 $\%$. Pengolahan citra pada landsat 8 tidak berbeda jauh dengan landsat 5 atau 7 namun dengan adanya kelebihan pada landsat 8 yang telah dijelaskan sebelumnya memungkinkan akurasi landsat 8 dapat lebih baik.

\section{SIMPULAN}

Pemetaan yang dihasilkan oleh analsis citra satelit landsat 8 dengan menggunakan skema klasifikasi palet warna untuk memetakan karakteristik substrat dasar perairan dangkal menghasilkan 5 (lima) kelas karakteristik substrat dasar perairan, yaitu pasir halus, pasir campur patahan karang mati, karang mati, terumbu karang dan lamun.

\section{SARAN}

Perlu adanya penelitian lanjutan tentang akurasi citra landsat 8 dengan pengecekan langsung di lapangan.

\section{DAFTAR PUSTAKA}

Budiman, S. dan B. Hasyim, (2005). Pemetaan Sebaran Mangrove, Padang Lamun, dan Terumbu Karang Menggunakan Data Pengindraan Jauh di Wilayah Pesisir Laut Arafura. Pertemuan Ilmiah Tahunan MAPIN XIV. Gedung Rektorat lt. 3 Kampus Institut Teknologi Sepuluh Nopember Surabaya, 14 - 15 September 2005.

Damayanti, R. (2012). Pemetaan Terumbu Karang Di Perairan Pulau Tabuha Kabupaten Banyuwangi Menggunakan Citra Satelit Quickbird. (Jurnal) Fakultas Pertanian, Universitas Trunojoyo: Madura.

Guntur, M. S, D. Prasetyo, dan Wawan. (2012). Pemetaan Terumbu Karang Teori, Metode dan Praktik. Penerbit Ghalia Indonesia, Cetakan I. Bogor.

Helmi. M, A. Hartoko, S. Herkiki, Munasik, dan S. Wouthuyzen, (2011). Analisis Respon Spektral dan Ekstraksi Nilai Spektral Terumbu Karang Pada Citra Digital Multispektral Satelit ALOSAVNIR di Perairan Gugus Pulau Pari, Kepulauan Seribu, Jakarta. Buletin Oseanografi Marina http://ejournal.undip.ac.id/index. php/buloma Oktober 2011.vol.1 $120-136$.

Joyce, K.E.; Phinn, S.R.; Roelfsema, C.M.; Neil, D.T.; Dennison, W.C. Combining Landsat ETM plus and Reef Check classifications for mapping coral reefs: A critical assessment from the southern Great Barrier Reef, Australia. Coral Reefs 2004, 23, 21-25. 
Lillesand, T.M. dan R.W. Kiefer. (1990). Penginderaan Jauh dan Interpretasi Citra (Terjemahan dari "Remote Sensing and Image Interpretation" oleh Dulbari). Gadjah Mada University Press. Yogyakarta.

Marendy, F. (2013). Studi Distribusi Terumbu Karang Menggunakan Citra Landsat di Taman Laut Bunaken, Sulawesi Utara. Ilmu Kelautan UNSRI. Vol. 9 edisi ke 2, Hal $1-6$.

Mumby, P. J., E. P. Green, A. J. Edwards, and C. D. Clark. (1997). Coral reef habitat mapping: how much detail can remote sensing provide? Marine Biology, 130: 193-202.

Pasaribu, A. R. (2008). Perubahan Luasan Terumbu Karang dengan Menggunakan Data Pengindraan Jauh di Perairan Barat Daya Pulau Moyo, Sumbawa. Fakultas Perikanan dan Ilmu Kelautan. Institut Pertanian Bogor. Skripsi.

Sirajuddin. H, S. Burhanuddin, dan S. Baja, (_ $)$. Analisis Perubahan Morfologi Pulau Kodingareng Keke Berdasarkan Interpretasi Citra Landsat Dan Spot. (Jurnal). http://pasca.unhas.ac.id/jurnal/fil es/47fe 7dd5911a477fc541f2b1a60 4e3e2.pdf. Diakses pada tanggal 23 Februari 2015.

Siregar, V. (2010). Pemetaan Substrat Dasar Perairan Dangkal Karang Congkak Dan Lebar Kepulauan Seribu Menggunakan Citra Satelit Quickbird. E-Jurnal Ilmu dan Teknologi Kelautan Tropis, Vol. 2, No. 1, Hal. 19-30.

Sugiarto, P. D. (2013). Landsat 8: Spesifikasi, Keunggulan dan Peluang Pemanfaatan Bidang Kehutanan. . Diakses pada tanggal 23 Februari 2015.
Suhana, P. M. (2015). Pemetaan Sebaran dan Kondisi Terumbu Karang Dengan memanfaatkan Citra Satelit Quickbird, Landsat-TM, EO-1 Hyperion, dan Alos-Avnir. (Jurnal) Mahasiswa Pascasarjana Ilmu Kelautan. Institut Pertanian Bogor. Sulma, S. Dan G. Winarso. (2003). Pemetaan Pengindraan Jauh untuk Pemetaan Terumbu Karang. Pusat Pengembangan Pemanfaatan dan Teknologi Pengindraan Jauh. LAPAN. Jakarta, Hal 68 -74.

http://www.usgs.gov/. Download Citra Satelit. Diakses pada tanggal 25 Februari 2015. 